\title{
Cáncer du col uterin et grossesse
}

\author{
Par R. L. Rochat.
}

Bull. de l'Ass. des Gyn. et. Obst. de L. Francaise. T. 2. No. 1-1950. París

El autor aprovecha el relato de una historia clínica para disertar sobre la asociación de cáncer y embarazo. Comienza por recordar que existe en la proporción de uno por seis mil, aunque es muy conocida la relatividad de las estadísticas. En todo caso, la rareza de fecundación en una mujer con cáncer cervical se explica porque éste aparece generalmente en menopáusica $(75 \%$ ) y en el $25 \%$ restante en mujeres de 40 años, edad en que el embarazo no es muy frecuente.

A Rochat se le hace muy discutible que la infecundidad se deba a la obstrucción del canal cervical por las regetaciones cancerosas y a las secreciones del tumor.

En lo que atañe al diagnóstico insiste en la diferenciación con la endometriosis y los papilomas del cutllo.

El cáncer repercute sobre el embarazo, el parto, el puerperio y el feto. La gravidez influye poderosamente sobre aquél. Son innegables los abortos y los partos prematuros por tal causa, explicable según Hinselmann por la intoxicación del huevo. Sobre el parto las consecuencias son notorias: desgarros cervicales por la rigidez de los tejidos, y que pueden avanzar sobre el segmento inferior, determinando hemorragias incoercibles. De ahí que se desaconseje el parto por las vías naturales. El puerperio es perturbado por serias infecciones, favorecidas por la debilidad consiguiente a la hemorragia.

El resultado experimental en relación con la inhibición que el embarazo ejercería sobre la evolución del cáncer no ha sido confirmado por la clínica. Cómo desconocer que la neoplasia encuentra anchos los caminos por la hiperemia local, la "supervitalidad" de los tejidos y el enriquecimiento de la red linfática?

La terapéutica se reduce a tres métodos: radioterapia, cirugía y la combinación de ambos. Como es nefasta la acción de los Rayos X y del radium sobre el feto, antes de comenzar la radioterapia habría que interrumpir el embarazo. El tratamiento electivo, según el autor, es el quirúrgico en bien de la madre y del hijo, mas no la cesárea seguida de histerectomía subtotal (la histerectomía total es la satisfactoria, pero no siempre es realizable) sino de extirpación de anexos para continuar aplicando radium intracervicalmente.

Ramón Francisco Sánchez 